\title{
The Value of Rainfall Forecasts in the Rainfed Rice Areas of the Philippines
}

\author{
Abedullah* $^{*}$ and Sushil Pandey**
}

\section{Abstract}

The value of rainfall forecasts for rainfed rice production in the Philippines is estimated under the assumption that farmers adjust the quantities of fertilizer and labor if rainfall forecasts are available. Using a panel of 46 rice farmers in Tarlac, Philippines, a heteroskedastic production function with growing season rainfall (July to October) as one of the independent variables is estimated. The expected value of rainfall forecasts under the assumption of simultaneous adjustments in both fertilizer and labor was estimated to be slightly more than $1 \%$ of the net return from rice production. Taking the rainfed rice area in the Philippines of 1.2 million ha and a net return of $\$ 446 /$ ha, the total value of the forecast was estimated to be $\$ 6.6$ million per year. The expected value was also estimated under the assumption that, instead of forecasts of rainfall amounts for each year, forecasts made are for rainfall "above average", "average", or "below average". The value of rainfall forecasts was found to be highest and ranged between 1.4\%-4.5\% of the net return when the forecast is 'above average'. The Philippine Atmospheric, Geophysical and Astronomical Services Administration (PAGASA) could belp farmers by investing more of its resource for the accurate prediction of above average' rainfall events.

\section{Introduction}

Agriculture is a risky enterprise with various kinds of risks involved in the production and marketing of agricultural products (Anderson and Dillon, 1992). Since risk arises due to the uncertainty about variables that affect production and profits, a reliable prediction of these uncertain variables will reduce risk. Input use and productivity when information

\footnotetext{
* Assistant Professor, University of Agriculture, Faisalabad.

** Agricultural Economist, Social Sciences Division (SSD), International Rice Research Institute, (IRRI), Philippines.
} 
about uncertain variables is available are likely to be different in comparison with the situation when no such information is available.

Although risk can arise from several sources, climatic uncertainty is the dominant source of risk, especially under rainfed conditions. Rainfall forecasts can partially help resolve uncertainties of rice production. In the Philippines, the Philippine Atmospheric, Geophysical and Astronomical Services Administration (PAGASA) provides seasonal rainfall forecasts that are classified as "above average", "below average" or "average". Although these forecasts are provided to help improve farmers' decisions about rice production, it is uncertain how valuable these forecasts are to rice farmers in economic terms. The allocation of more resources to forecast rainfall is desirable if the additional value of the rainfall forecast is higher than the additional cost of providing such a forecast. Estimates of the value of rainfall forecasts can be a useful guide in determining the optimal resource allocation for generating forecasts. To aid in this task, this study attempts to estimate the potential value of rainfall forecasts to rice farmers of Tarlac, Central Luzon, Philippines.

\section{A Conceptual Model for Estimating the Value of Information}

The value of information can be derived using the standard model of agricultural risk analysis (Anderson et al, 1977). Let $\Phi$ be the stochastic variable (i.e. state of nature) beyond the control of the decision-maker. If $\mathrm{X}$ is a vector of variable inputs that are manipulated by the decision-maker, the return $\mathrm{g}(\Phi, \mathrm{X})$ earned depends on the state of nature and the vector of inputs. The function $\mathrm{g}(\Phi, \mathrm{X})$ embodies input, output, and price relationships. In the absence of forecast information, decisions are based on the prior belief about the probability distribution of the stochastic variable. Let this prior probability density function be denoted by $f(\Phi)$. A riskneutral decision-maker selects ${ }^{*}$ to maximize the expected return $\int_{g}(\Phi, X)$ $f(\Phi) \mathrm{d} \Phi$ from the production process. The optimal decision and profits based on prior information only are the prior optimal level of inputs and the prior optimal profits, respectively. On the other hand, if the economic agent has a forecast of the value of $\Phi$ (i.e. about the state of nature) before the selection of the input vector, the decision-maker will select $\hat{X}$ to maximize $\mathrm{g}(\Phi, \mathrm{X})$ for each $\Phi$. Let the maximized value of the profit be represented by $g(\Phi, \hat{X})$. The expected value of information "V" for risk-neutral farmers is the difference between expected profit derived with and without the information and is obtained as: 


$$
\mathrm{V}=\int g(\Phi, \hat{\mathrm{X}}) h(\Phi) d \Phi-\int g(\Phi, \stackrel{*}{\mathrm{X}}) f(\Phi) d \Phi
$$

where, V stands for the value of information to risk-neutral farmers and $h$ $(\Phi)$ is the probability density of uncertain event revised using the forecast information.

Following the expected utility model of decision-making under risk, risk-averse farmers are assumed to maximize the expected utility of profit (Anderson et al, 1977). Analogous to the model above for risk-neutral farmers, expected utility is estimated 'with' and 'without' information and the difference in the expected utility can be regarded as an indicator of the expected value (in utility terms) of rainfall predictor to risk-averse farmers. As the differences in utility that are ordinal in scale are meaningless, we have used the method followed by Byerlee and Anderson (1982) to obtain the value of information in money terms.

$$
\mathrm{E}[U(\hat{\Pi}-V)]-\mathrm{E}[U(\dot{\Pi})]=0
$$

where, $\mathrm{E}[U(\dot{\Pi})]$ is the expected utility of the prior optimal act and $E[U(\hat{\Pi}-V)]$ is the expected utility of the optimal act derived using the prediction that costs $\$ \mathrm{~V}$ to acquire.

To implement model (1), it is essential to quantify the effect of inputs $(\mathrm{X})$ and stochastic variables $(\Phi)$ on agricultural output. Such a relationship can be quantified using a production function. To implement mode1 (2), the utility function that relates the level of profit to utility is also needed. A convenient form of the utility function is the constant partial risk-averse function (CPRA). It is specified as.

$$
U(\Pi)=(1-S) \Pi^{(1-S)}
$$

where, ' $\mathrm{S}$ ' is the risk aversion coefficient. This form of utility function has been widely used in applied research (Sillers, 1980; Smith and Umali, 1985; Rosegrant and Roumasset, 1985).

\section{Description of the Study Area}

Socio-economic monitoring of the rice production practices of 46 farmers from the municipality of Victoria, Tarlac, Philippines was initiated in 
1990. Rice is grown in the rainy season with most of the land being left fallow in the dry season. The area has good market access and is well-linked with the town economy of Tarlac. Farmers are engaged in various off-farm and non-farm activities during the dry season to supplement their incomes. The means and the coefficients of variation (CV) of output and input variables are reported in Table-1. Based on the long-term weather record (1976-1995), the mean annual rainfall in Victoria is $1,649 \mathrm{~mm}$. The variation in rainfall during the rice-growing season (July-October) is shown in Figure 1.

Plot level data from the sample of 46 farmers were collected for the period 1990-95. All inputs and outputs were recorded in a survey questionnaire, which was administered every year to the same group of farmers. Unbroken panel data for 420 plots for each of the six years were utilized for estimating the production function. The only source of uncertainty considered was rainfall which was specified in the model as the total rainfall during the rice-growing season (July-October). The rainfall values are the same for all plots in a given year but differ from year to year. For biological reasons, it would have been more appropriate to specify rainfall as weekly or monthly total as compared to the seasonal total. However, we used the seasonal total, as a reliable estimation of the production responses for weekly or monthly rainfall using production data for only six years would have been constrained by the limited degrees of freedom.

\section{Production Function Estimation}

When production functions are estimated using a combination of cross-section and time-series data, heteroskedasticity may lead to asymptotically inefficient parameter estimates (Just and Pope, 1978). The Breusch-Pagan test rejected the null hypothesis of homoskedasticity at the $5 \%$ leve1. To correct for heteroskedasticity, a multistage production function estimation technique suggested by Antle (1983) was used. A quadratic production function as specified in equation (4) was used.

$$
\begin{aligned}
& \mathrm{Y}=\alpha_{1}+\alpha_{2} \mathrm{X}_{1}+\alpha_{3} \mathrm{X}_{1}^{2}+\alpha_{4} \mathrm{X}_{2}+\alpha_{5} \mathrm{X}_{2}^{2}+\alpha_{6} \mathrm{Z}+\alpha_{7} \mathrm{Z}^{2}+ \\
& \alpha_{8} \mathrm{X}_{1} \mathrm{X}_{2}+\alpha_{9} \mathrm{X}_{1} \mathrm{Z}+\alpha_{10} \mathrm{X}_{2} \mathrm{Z}+v
\end{aligned}
$$

where, $\mathrm{Y}, \mathrm{X} 1, \mathrm{X} 2$, and $\mathrm{Z}$ represent yield, total 1abor, fertilizer (total of $\mathrm{N}$, $\mathrm{P}$, and $\mathrm{K}$ ), and total rainfall during the rice production period (from July to October), respectively. The stochastic error term is represented by $v$. The 
per hectare input use (labor, seed, herbicide, pesticide and elemental nutrients fertilizer (i.e. the sum of $\mathrm{N}, \mathrm{P}$, and $\mathrm{K}$ ) and output with descriptive statistics is given in Table-1.

The parameter estimates using Antles' method are presented in Table-2. The coefficients of labor, labor $^{2}$, fertilizer, fertilizer ${ }^{2}$, rainfall and rainfal1 ${ }^{2}$ all have the expected signs. The joint effects of rain and labor, and rain and fertilizer are positive and significant. The interaction term between fertilizer and labor is negative, indicating that these two inputs have a substitute relationship in rice production.

\section{Procedure for Estimating the Value of Rainfall Forecast}

In valuing the forecasts, a prior probability distribution of rainfall is required. We assumed farmers' prior probability of rainfall to be equivalent to the historical distribution of total rainfall during the rice production period. The probability distribution was estimated by applying the sparse data rule (Anderson et al, 1977) to the historical rainfall for the period $1977-95$. For a given value of the decision variable, profits were generated for each year by substituting the rainfall for that particular year into the production function. The expected profit was then calculated by using the corresponding rainfall probability weights. This process was repeated for all possible values of the decision variable and the value of the decision variable that generated the maximum expected profit was taken as the prior optimal decision. For risk-averse farmers, the prior maximal expected utility was similarly calculated by substituting the profit for each decision into equation (3) and using the corresponding probability weights. Siller (1980) concluded that $78 \%$ of rice farmers in Nueva Ecija, Philippines lie in the two intermediate categories of risk aversion. The $S=0.8$ is the common end point of these two categories. The value of risk aversion coefficient used in this study was 0.8 .

The rainfall forecast for each year was generated by random sampling from the discrete probability distribution of the historical rainfall data. Assuming that the prediction is perfect, optimal profit for this forecast was then obtained using the estimated production function. As prediction is assumed to be perfect, the probability distribution of the forecast is also the historical probability distribution of rainfall. Using the historical distribution, the expected profit when a perfect predictor of rainfall is available was then calculated. The difference between this expected profit and the expected profit of the prior optimal act is the expected value of the perfect predictor of rainfall. A similar procedure was used for the risk-averse case and equation (2) was utilized to obtain the 
value of a perfect predictor to a risk-averse farmer. Estimation of the value of the perfect predictor is convenient as it avoids the need to explicitly obtain the likelihood function, which is an indicator of the accuracy of the predictor. Since no rainfall predictor can be perfect, the estimated value of the predictor can be considered as the upper limit of the value of rainfall forecast.

As rainfall forecasts in the Philippines are provided as 'average', 'below average', or 'above average', we also estimated the value of these forecasts. The 19-year historical July-October total rainfall fluctuated between 700-1650 $\mathrm{mm}$ (IRRI, Various Issues). We divided this total range of rainfall into three categories, below average (between 700 and $1000 \mathrm{~mm}$ of rainfa11), average (between 1050 and $1300 \mathrm{~mm}$ of rainfa11), and above average (between 1350 and $1650 \mathrm{~mm}$ of rainfall). To calculate the value of the perfect predictor, predicted rainfall values were limited within the range defined by these prediction categories. The prior optimal expected profit was obtained as before. The posterior expected profit was estimated by using the optimal profits for each perfect prediction (randomly selected, within the particular rainfall category) and the corresponding conditional probabilities. The difference between these two expected profits is the value of a particular category of forecast for a risk-neutral farmer. A similar procedure was used for the risk-averse case.

Labor and fertilizer are the two decision variables considered. Farmers may adjust either or both of them from their prior optimal values if rainfall forecasts are available. We estimated the value of rainfall forecast under the assumptions that (a) only labor is adjusted to its posterior optimal value while the fertilizer is fixed at its sample average, (b) only fertilizer is adjusted to the posterior optimal value while labor is kept fixed at its sample average, and (c) both labor and fertilizer are adjusted simultaneously to their posterior optimal values.

\section{Value of Rainfall Forecasts}

The estimated values of a perfect rainfall predictor for risk-neutral and risk-averse farmers are presented in Table-3. The expected value of a rainfall forecast, if farmers are assumed to adjust fertilizer application when rainfall predictions are available, are $\$ 1.92$ and $\$ 2 /$ ha for risk-neutral and risk-averse farmers, respectively. These values account for $0.43 \%$ and $0.46 \%$ of the net return from rice production in the study area. The expected values of rainfall forecasts under the assumption that only labor is adjusted are $\$ 4.08$ and $\$ 4.29 /$ ha for risk-neutral and risk-averse farmers, respectively. 
These comprise $0.92 \%$ and $0.96 \%$, respectively, of the net return from rice production.

The expected values of a perfect predictor of rainfall (under the assumption that farmers adjust fertilizer and labor simultaneously) for riskneutral and risk-averse farmers are $\$ 5.50$ and $\$ 5.79 /$ ha, respectively. In terms of percentage of the net return these values are $1.23 \%$ and $1.29 \%$, respectively. The effect of risk aversion on the value of rainfall forecast was found to be minimal.

The cost of acquiring information was not included in the above calculation, implying that the results indicate the expected gross benefits of the forecast. Net benefits depend on the cost of obtaining and using information. Gross benefits, as estimated here, are useful to indicate the maximum amount a farmer would be willing to pay to obtain the forecast.

The expected values of the forecast under the assumption that the forecasts are 'below average' (between 700 and $1000 \mathrm{~mm}$ of rainfal1), 'average' (between 1050 and $1300 \mathrm{~mm}$ of rainfa11) or 'above average' (between 1350 and $1650 \mathrm{~mm}$ of rainfall) were also estimated (Table-4). In the case of simultaneous adjustment of fertilizer and labor, values vary from $\$ 1.58$ to $\$ 20 /$ ha depending on the type of the forecast and the assumption about the risk attitude of farmers. In terms of percentage of net return, these values lie in the range of $0.35-4.52 \%$. The 'above average' forecasts are found to be more valuable to farmers than 'below average' and 'average' forecasts. The PAGASA could hence help farmers more by investing more of its resource for the accurate prediction of 'above average' rainfall events.

The estimates of the value of rainfall forecasts obtained here are only a small fraction of the net return. In rainfed agriculture where rainfall is the major source of uncertainty, such a low value may appear to be somewhat surprising. This may partly be the result of the model specification in which rainfall is included as the seasonal total and the only two decision variables considered are labor and fertilizer application. Nevertheless, estimates derived here are comparable to those obtained for other countries. Mejelde et al, (1988) reported the value of rainfall forecasts varying from $5 \%$ to $13 \%$ of the net return in corn production in Illinois. Pannell (1994) estimated the value of information from herbicide decision making in wheat production in Australia to be between $0-15 \%$ of the gross margin from the crop. Marshall et al, (1996) estimated the value of seasonal forecasts for dryland wheat production in Australia to be between $0-6 \%$ of the net return. Even though the value of the forecast 
expressed as a percentage of net return may be small, the total absolute value can be quite large depending on the size of the area covered by the forecast. Taking the rainfed rice area in the Philippines of 1.2 million hectare and a net return of $\$ 446 / \mathrm{ha}$, the total benefit to rainfed rice farmers would be $\$ 6.6$ million per year even if the value of the forecast is only $1.23 \%$ of the net return.

\section{Concluding Remarks}

Overall, the expected value of a hypothetical perfect predictor of rainfall is found to be between $\$ 2 / \mathrm{ha}-\$ 6 /$ ha for moderate risk-averse farmers, which is little higher than $1 \%$ of the net return earned by farmers from rice production in the study area. This is an upper bound estimate of the value of a rainfall predictor, since the prediction accuracy of a realistic predictor is likely to be less than $100 \%$. As rainfall prediction in the Philippines is provided cost free, this is also an estimate of its net value to farmers. The effect of risk aversion on the value of the forecast was found to be minimal. Our results also indicate that the value of information is asymmetrical, with the 'above average' forecast being four times more valuable than the 'average' forecast and about two times more valuable than the 'below average' forecast. An important implication of this finding is that additional efforts by PAGASA to correctly predict the 'above average' rainfall events may be justifiable. Overall, the average value of a perfect predictor of seasonal rainfall to the rainfed rice farmers of the Philippines was estimated to be $\$ 6.6$ million per year.

The value of the forecast depends critically on the quality and the timeliness of the forecast (Mjelde et al., 1988). Forecasts are valuable only if they are received before inputs have been applied. We did not investigate the timeliness issue due to limitations of data for estimating production functions that adequately capture temporal interactions between managed inputs and rainfall. Similarly, we have considered rainfall as the only source of uncertainty on the assumption that rainfall variability is the major source of risk in rainfed rice production. Further expansion of the approach used to include these refinements is suggested. 
Table-1: Average per hectare Input and Output Use in Victoria, Tarlac, Philippines.

\begin{tabular}{llcc}
\hline \multicolumn{1}{c}{ Input/output } & \multicolumn{1}{c}{ Units } & Average & Standard deviation \\
\hline Total labor & (days/ha) & 55 & 15 \\
Seed & $(\mathrm{kg} / \mathrm{ha})$ & 110 & 47 \\
Fertilizer $(\mathrm{NPK})$ & $(\mathrm{kg} / \mathrm{ha})$ & 94 & 42 \\
Herbicide & $(\mathrm{kg} \mathrm{a.i.} / \mathrm{ha})$ & 0.14 & 0.21 \\
Pesticide & (kg a.i./ha) & 0.09 & 0.14 \\
Yield & (tons/ha) & 3.35 & 1.07 \\
\hline
\end{tabular}

a. Includes family labor and hired labor.

Table-2: Quadratic Production Function Estimates with Antle's Technique in Victoria, Tarlac, Philippines ${ }^{\mathrm{a}}$.

\begin{tabular}{|c|c|c|}
\hline Explanatory variables & Coefficients & Standard errors \\
\hline Intercept & $-72.9 \mathrm{E}-03^{\mathrm{ns}}$ & $134.1 \mathrm{E}-02$ \\
\hline Labor & $30.2 \mathrm{E}-03^{*}$ & 18.2E-03 \\
\hline Fertilizer & $18.2 \mathrm{E}-03^{* * *}$ & 7.6E-03 \\
\hline Rain & $1.4 \mathrm{E}-03^{\mathrm{ns}}$ & $1.6 \mathrm{E}-03$ \\
\hline Labor $^{2}$ & $-0.2 \mathrm{E}-03^{* * * *}$ & $9.1 \mathrm{E}-05$ \\
\hline Fertilizer $^{2}$ & $-3.8 \mathrm{E}-05^{* * * *}$ & $1.7 \mathrm{E}-05$ \\
\hline $\operatorname{Rain}^{2}$ & $-1.1 \mathrm{E}-06^{* *}$ & $5.6 \mathrm{E}-07$ \\
\hline Labor*Fertilizer & $-0.2 \mathrm{E}-03^{* * *}$ & $7.1 \mathrm{E}-05$ \\
\hline Labor*Rain & $1.7 \mathrm{E}-05^{*}$ & $1 \mathrm{E}-05$ \\
\hline Fertilizer*Rain & $5.1 \mathrm{E}-06^{* * * *}$ & $4.4 \mathrm{E}-07$ \\
\hline $\mathrm{R}^{2}$ & 0.25 & \\
\hline $\mathrm{n}$ & 420 & \\
\hline
\end{tabular}


Table-3: Total expected value of forecast in $(\mathbf{\$} / \mathbf{h a})$ under different input adjustment in Victoria, Tarlac, Philippines

\begin{tabular}{lcc}
\hline \multicolumn{1}{c}{ Forecast and adjustment of } & \multicolumn{2}{c}{ Value of rainfall forecast ${ }^{\mathbf{a}}$} \\
\cline { 2 - 3 } inputs & Risk-neutral & Risk-averse $^{\text {Fis }}$ \\
\hline Fertilizer adjustment only & 1.92 & 2.04 \\
& $(0.43)$ & $(0.45)$ \\
Labor adjustment only & 4.08 & 4.29 \\
& $(0.92)$ & $(0.96)$ \\
Simultaneous adjustment & 5.50 & 5.79 \\
of fertilizer and labor & $(1.23)$ & $(1.29)$ \\
\hline
\end{tabular}

${ }^{a}$ Value in parenthesis represents the percentage of net return.

Table-4: The expected value of different rainfall forecasts for rice production period in $(\$ /$ ha) under different input adjustment in Victoria, Tarlac, Philippines.

\begin{tabular}{|c|c|c|}
\hline \multirow[t]{2}{*}{ Forecast and adjustment of inputs } & \multicolumn{2}{|c|}{ Value of rainfall forecast ${ }^{a}$} \\
\hline & Risk-neutral & Risk-averse \\
\hline \multicolumn{3}{|l|}{ Below average $(700-1000) \mathrm{mm}$. } \\
\hline Fertilizer adjustment only & $\begin{array}{l}1.42 \\
(0.32)\end{array}$ & $\begin{array}{l}1.50 \\
(0.34)\end{array}$ \\
\hline Labor adjustment only & $\begin{array}{c}2.71 \\
(0.61)\end{array}$ & $\begin{array}{c}2.92 \\
(0.65)\end{array}$ \\
\hline $\begin{array}{l}\text { Simultaneous adjustment of } \\
\text { fertilizer and labor }\end{array}$ & $\begin{array}{c}3.42 \\
(0.77)\end{array}$ & $\begin{array}{l}3.67 \\
(0.82)\end{array}$ \\
\hline \multicolumn{3}{|l|}{ Average (1050-1300) mm. } \\
\hline Fertilizer adjustment only & $\begin{array}{c}0.50 \\
(0.11)\end{array}$ & $\begin{array}{c}0.58 \\
(0.13)\end{array}$ \\
\hline Labor adjustment only & $\begin{array}{c}1.25 \\
(0.28)\end{array}$ & $\begin{array}{c}1.33 \\
(0.30)\end{array}$ \\
\hline $\begin{array}{l}\text { Simultaneous adjustment of } \\
\text { fertilizer and labor }\end{array}$ & $\begin{array}{c}1.58 \\
(0.35)\end{array}$ & $\begin{array}{c}1.71 \\
(0.38)\end{array}$ \\
\hline Above average (1350-1650) mm. & & \\
\hline Fertilizer adjustment only & $\begin{array}{c}6.17 \\
(1.38)\end{array}$ & $\begin{array}{c}6.50 \\
(1.46)\end{array}$ \\
\hline Labor adjustment only & $\begin{array}{l}13.75 \\
(3.08)\end{array}$ & $\begin{array}{l}14.17 \\
(3.18)\end{array}$ \\
\hline $\begin{array}{l}\text { Simultaneous adjustment } \\
\text { of fertilizer and labor }\end{array}$ & $\begin{array}{l}19.33 \\
(4.33)\end{array}$ & $\begin{array}{l}20.17 \\
(4.52)\end{array}$ \\
\hline
\end{tabular}

a Value in parenthesis represents the percentage of net return. 


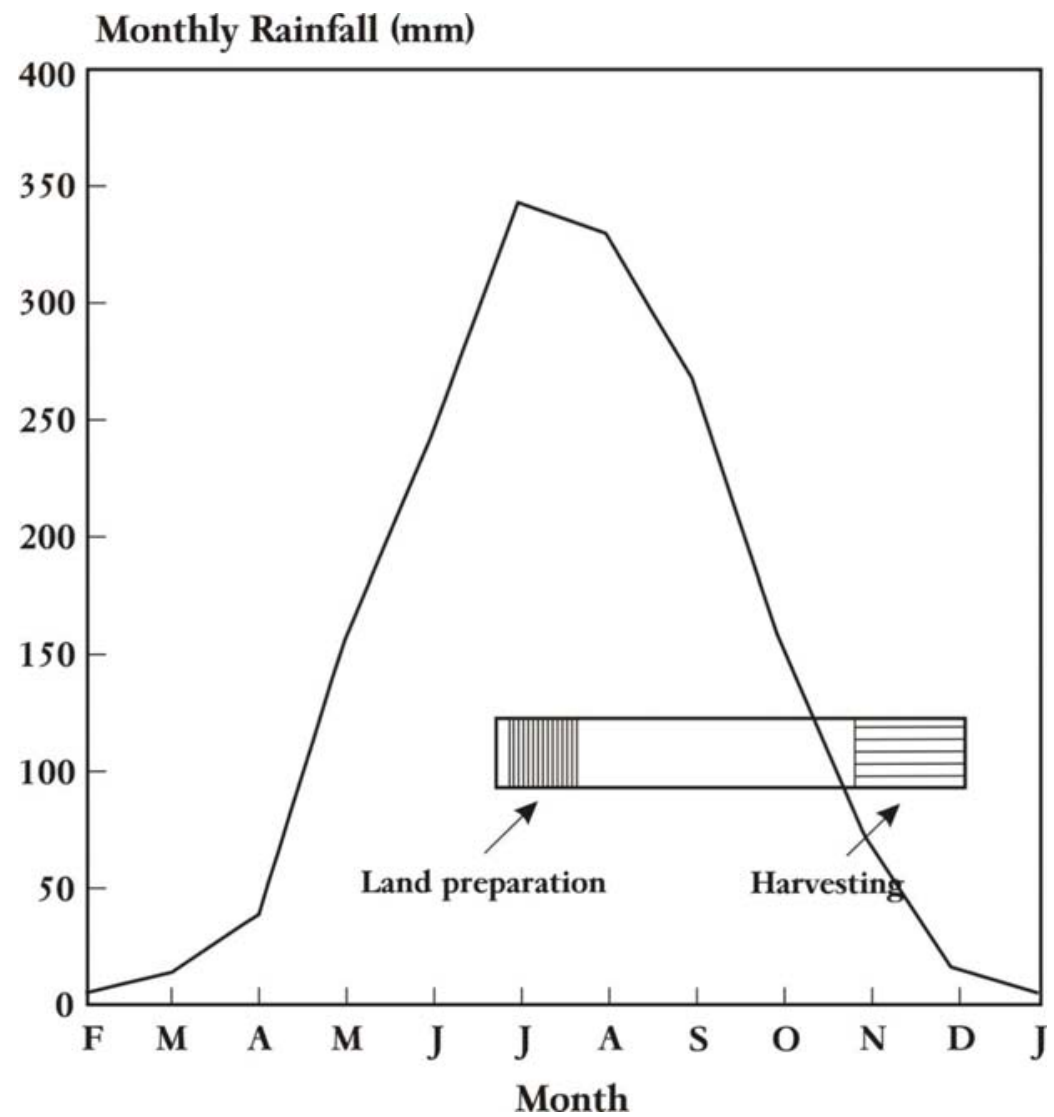

Figure 1. Average monthly rainfall over 1977-95, Victoria, Tarlac, Philippines. 


\section{References}

Anderson, J.R; Dillon; J.D. and Hardaker, J.B., 1977, Agricultural Decision Analysis. Iowa State University Press, Ames, Iowa.

Anderson J.R and Dillon J.L., 1992, Risk analysis in dryland farming systems. Food and Agriculture Organization of the United Nations, Farm Systems Management Series 2.

Antle, J.M., 1983, Testing the Stochastic Structure of Production: A Flexible Moment-Based Approach. Journal of Business and Economic Statistics, 1(3), pp.192-201.

Byerlee, D. R. and Anderson, J. R., 1982, Risk, Utility and the Value of Information in Farmer Decision Making. Review of Marketing and Agricultural Economics, 50(3), pp.231-246.

IRRI, Various Issues on Climate Data from Agronomy, Plant Physiology and Agroecology Division. International Rice Research Institute (IRRI).

Just, R.E and Pope, R.D., 1978, Stochastic Specification of Production Functions and Economic Implications. Journal of Econometrics, 7(1), pp.67-86.

Marshall, G.R, Parton, K.A. and Hammer, G.L., 1996, Risk Attitude, Planting Conditions and the Value of Seasonal Forecasts to a Dryland Wheat Grower. Australian Journal of Agricultural Economics, 40, (3) (December 1996), pp. 211-233.

Mjelde J. W; Steven T. Sonka; Bruce L. Dixon; and Peter J. Lamb, 1988, Valuing Forecast Characteristics in a Dynamic Agricultural Production System. American Journal of Agricultural Economics, 70 (3), pp. 674-684.

Pannell J. David, 1994, The Value of Information in Herbicide Decision Making for Weed Control in Australian Wheat Crops. Journal of Agricultural Resource Economics, 19, (2), pp. 366-381.

Rosegrant, M.W. and Roumasset J.A., 1985, The Effect of Fertilizer on Risk: A Heteroscedastic Production Function With Measurable Stochastic Inputs. Australian Journal of Agricultural Economics, 29(2), pp.107121. 
Sillers, D.A., 1980, Measuring Risk Preferences of Rice Farmers in Nueva Ecija (Philippines), An Experimental Approach. PhD Dissertation, Yale University.

Smith, J. and Umali, G., 1985, Production Risk and Optimal Fertilizer Rates: An Application of the Random Coefficient Mode1. American Journal of Agricultural Economics, (August 1985). pp. 654-659. 